Article

\title{
Effects of Lipids and Emulsifiers on the Physicochemical and Sensory Properties of Cosmetic Emulsions Containing Vitamin E
}

\author{
Lucia Montenegro *, Lucia Rapisarda, Carmen Ministeri, and Giovanni Puglisi \\ Department of Drug Sciences, University of Catania, V.le A. Doria 6, 95125 Catania, Italy; \\ E-Mails: luciarapisarda12@hotmail.it (L.R.); carmenmini@hotmail.it (C.M.); puglisig@unict.it (G.P.) \\ * Author to whom correspondence should be addressed; E-Mail: lmontene@unict.it; \\ Tel.: +39-095-738-4010; Fax: +39-095-738-4211.
}

Academic Editor: Carla Villa

Received: 31 December 2014 / Accepted: 6 March 2015 / Published: 18 March 2015

\begin{abstract}
Sensory properties are fundamental in determining the success of a cosmetic product. In this work, we assessed the influence of different oils and emulsifiers on the physicochemical and sensory properties of anti-ageing cosmetic $\mathrm{O} / \mathrm{W}$ emulsions containing vitamin $\mathrm{E}$ acetate as active ingredient. No clear correlation between physicochemical properties and sensory characteristics was evidenced. Sensorial evaluation of these formulations pointed out that the emulsifier systems affected the perceived oiliness and absorbency during application of the product, thus influencing its acceptance. These results suggest the need for more detailed studies on the physicochemical factors involved in determining the consumers' acceptance.
\end{abstract}

Keywords: sensory evaluation; cosmetic emulsions; vitamin E; vehicle effects

\section{Introduction}

Vitamin E or $\alpha$-tocopherol, one of the better-known antioxidants used in cosmetic formulations, is naturally occurring in human skin [1], where it prevents lipid peroxidation at cell membrane level, stabilizing especially those membranes with high content of polyunsaturated fatty acids. Vitamin E is present in high concentration in the deepest layers of the stratum corneum (SC) [2], representing the primary defense of the skin from the oxidative stress induced by UV exposure and pollutants. The role of vitamin $\mathrm{E}$ as a protective agent against reactive oxygen species is well documented [3]. Several 
studies evidenced the efficacy of topical application of vitamin E against UV-induced cutaneous damage, carcinogenic and mutagenic activity of ionizing radiation, and oxidant agents [4-6]. Dietary supplementation with vitamin E proved less effective in preventing cutaneous lipid peroxidation than topical treatment, likely because higher concentrations of this vitamin were achieved in the skin tissues after its topical administration [7]. In skin care products, vitamin E is used as moisturizing and particularly as anti-ageing, due to its ability to reduce fine lines, wrinkles and sagging induced by photo-ageing [8-10]. However, due to its sensitivity to atmospheric oxygen, vitamin $\mathrm{E}$ is poorly stable in topical formulations. Therefore, this vitamin is generally used as acetic ester (tocopheryl acetate), which is biologically inactive but it can be converted to vitamin E after penetrating into the skin $[11,12]$. In the last decades, many studies have highlighted the efficacy of tocopheryl acetate in improving photoaged skin $[13,14]$.

The success of a cosmetic formulation depends not only on the efficacy of the active ingredient(s) but also on the consumer acceptance that is significantly affected by the sensory properties of the product. Therefore, many studies have been focused on sensory evaluations of cosmetics to fulfill consumers' needs by formulating products that offer both adequate efficacy and aesthetic characteristics [15-17]. Recently, Lukic et al. [18], evaluating the effects of emollients on textural, sensorial and in vivo skin performance of cosmetic $\mathrm{O} / \mathrm{W}$ emulsions, reported that the oily phase composition affected all investigated characteristics, evidencing that the replacement of only one oil could make a significant change.

In addition, emulsifiers may play a significant role in determining the rheological characteristics of cosmetic emulsions and active ingredient skin permeation from these vehicles [19].

In this work, we evaluated the influence of both different oils and emulsifier systems on the physicochemical and sensory properties of cosmetic $\mathrm{O} / \mathrm{W}$ emulsions. Being designed as anti-ageing products, all these formulations contained vitamin $\mathrm{E}$ acetate as active ingredient.

Viscosity, spreadability and occlusive properties of these formulations were determined and correlated with the results of sensory evaluations and in vivo efficacy tests.

\section{Experimental Section}

\subsection{Materials}

The following ingredients were a kind gift from Basf (Ludwigshafen, Germany): decyl oleate (Cetiol V ${ }^{\circledR}$, DO), caprylic/capric triglyceride (Myritol 318 ${ }^{\circledR}$, MYR). Isopropyl myristate (IPM), glycerin, polysorbate 60 (Tween $60^{\circledR}$ ) and disodium EDTA (ethylenediaminetetraacetic acid) were supplied by Galeno (Carmignano-Prato, Italy). Steareth-21 (Brij $721^{\circledR}$ ) and Steareth-2 (Brij $72^{\circledR}$ ) were bought from Sigma-Aldrich (Milan, Italy). Sinerga (Gorla Maggiore, Varese, Italy) kindly supplied methylchloroisothiazolinone and methylisothiazolinone (Kathon $\left.\mathrm{CG}^{\circledR}\right)$, imidazolidinyl urea $\left(\operatorname{Gram} 1^{\circledR}\right.$ ). Vitamin E acetate, ethylexylstearate (Tegosoft $\mathrm{OS}^{\circledR}$ ), C12-15 alkyl benzoate (Acemoll TN), sorbitan monostearate (Span $60^{\circledR}$ ), cetearyl alcohol (CSA), cetearyl glucoside and cetearyl alcohol (Montanov $68^{\circledR}$ ) were bought from Acef (Fiorenzuola D’Arda-Piacenza, Italy). Parfum was a gift from Muller and Koster (Liscate-Milan, Italy). 


\subsection{Preparation of $\mathrm{O} / \mathrm{W}$ Emulsions}

Nine cosmetic $\mathrm{O} / \mathrm{W}$ emulsions were prepared and their composition is reported in Table 1. Samples were prepared by hot-cold procedure, in an open system. Water phase (phase B) was added to oil phase containing vitamin $\mathrm{E}$ acetate $1 \% \mathrm{w} / \mathrm{w}$ (phase A), both previously heated to $70{ }^{\circ} \mathrm{C}$, under vigorous stirring (Turbomixer Silverson SL2, Silverson Machines Inc., East Longmeadow, MA, USA). The resulting emulsion was then cooled to $40{ }^{\circ} \mathrm{C}$ and the preservatives (phase C) and the fragrance (phase D) were added. Then, the formulation was cooled to room temperature under slow and continuous stirring. The samples were stored in airtight glass jars until used.

\subsection{Viscosity and pH Measurements}

Viscosity and $\mathrm{pH}$ of all emulsions were determined $48 \mathrm{~h}$ after their preparation to allow them to settle down. Viscosity determinations (mPas) were performed on a Mettler Rheomat RM 260 rheometer (Mettler-Toledo, Greinfensee, Switzerland) using MSDIN 125 concentric cylinders, at room temperature. Samples were tested with shear rates that progressively increased from 0 to $10 \mathrm{~s}^{-1}$, remained constant at $10 \mathrm{~s}^{-1}$ and decreased to $0 \mathrm{~s}^{-1}$, with a $60 \mathrm{~s}$ duration of each step. Samples of the emulsions were left to settle over $10 \mathrm{~min}$ at room temperature before measurements. Viscosity values were determined at shear rate $3 \mathrm{~s}^{-1}$ for $60 \mathrm{~s}$.

The $\mathrm{pH}$ of each formulation, diluted with water to one-tenth of its original concentration [20] was determined by a Crison $\mathrm{pH}$-meter, model Basic 20, at room temperature. Previous evaluations evidenced that $\mathrm{pH}$ values were not affected by the sample dilution used.

\subsection{Spreadability}

The determination of spreadability was performed according to the method described by Chaudhary and Verma [21]. Briefly, $1 \mathrm{~g}$ of sample was placed between two glass slides (diameter $=20 \mathrm{~cm}$ ). Then, a weight (200 g) was carefully put on the center of the upper slide. After $1 \mathrm{~min}$, the weight was removed and the diameter $(\mathrm{cm})$ of the spread area was measured.

\subsection{Occlusive Properties}

In vitro occlusion tests were carried out according to the procedure described by Wissing et al. [22]. Beakers $(100 \mathrm{~mL})$ were filled with $50 \mathrm{~mL}$ of water, covered with filter paper (cellulose acetate filter, $90 \mathrm{~mm}$, perfecte 2, Cartiera Cordenons), sealed and weighted. Then, $200 \mathrm{mg}$ of each formulation were spread evenly with a spatula on the filter surface $\left(18.8 \mathrm{~cm}^{2}\right.$; applied amount $\left.10.6 \mathrm{mg} / \mathrm{cm}^{2}\right)$. The samples were stored at $32{ }^{\circ} \mathrm{C}$ and $50 \%-55 \% \mathrm{RH}$ for $24 \mathrm{~h}$. At the end of the experiment, the cream formed a thin solid film that was completely removed using a spatula. Then, the samples were weighted, giving the water loss due to evaporation. Beakers containing $50 \mathrm{~mL}$ of water and covered with filter paper but without applying any formulation were used as reference. Each experiment was performed in triplicate. The occlusion factor $F$ was calculated according to Equation (1):

$$
F=100 \times[(A-B) / A]
$$


where $A$ is the water loss without any formulation (reference) and $B$ is the water loss with the formulation under investigation.

\subsection{Stability Studies}

All formulations were stored in airtight glass containers at room temperature for 1 year. Appearance, color, odor, $\mathrm{pH}$, viscosity, spreadability and occlusive properties were assessed at intervals (1 month, 2 months, 3 months, 6 months, 12 months). Color and appearance of the formulations were evaluated by a visual method and odor by olfaction. These assessments took into consideration the initial attributes of the formulations and changes that may or may not have occurred during the study period.

Table 1. Composition $(\% w / w)$ of cosmetic $\mathrm{O} / \mathrm{W}$ emulsions containing tocopherol acetate $(1 \% w / w)$.

\begin{tabular}{|c|c|c|c|c|c|c|c|c|c|}
\hline Ingredients & $\mathbf{A}$ & $\mathbf{A}_{1}$ & $\mathbf{A}_{2}$ & B & $\mathbf{B}_{1}$ & $\mathbf{B}_{2}$ & $\mathbf{C}$ & $\mathrm{C}_{1}$ & $\mathrm{C}_{2}$ \\
\hline \multicolumn{10}{|l|}{ Phase A } \\
\hline CSA & 4.0 & 4.0 & 4.0 & 4.0 & 4.0 & 4.0 & 4.0 & 4.0 & 4.0 \\
\hline Acemoll TN & 3.0 & 3.0 & 3.0 & 3.0 & 3.0 & 3.0 & 3.0 & 3.0 & 3.0 \\
\hline Tegosoft OS & 3.0 & 3.0 & 3.0 & 3.0 & 3.0 & 3.0 & 3.0 & 3.0 & 3.0 \\
\hline DO & 2.0 & - & - & 2.0 & - & - & 2.0 & - & - \\
\hline MYR & - & 2.0 & - & - & 2.0 & - & - & 2.0 & - \\
\hline IPM & - & - & 2.0 & - & - & 2.0 & - & - & 2.0 \\
\hline Brij 72 & 3.0 & 3.0 & 3.0 & - & - & - & - & - & - \\
\hline Brij 721 & 2.0 & 2.0 & 2.0 & - & - & - & - & - & - \\
\hline Tween 60 & - & - & - & 3.0 & 3.0 & 3.0 & - & - & - \\
\hline Span 60 & - & - & - & 2.0 & 2.0 & 2.0 & - & - & - \\
\hline Montanov 68 & - & - & - & - & - & - & 5.0 & 5.0 & 5.0 \\
\hline \multicolumn{10}{|l|}{ Phase B } \\
\hline Glycerin & 3.0 & 3.0 & 3.0 & 3.0 & 3.0 & 3.0 & 3.0 & 3.0 & 3.0 \\
\hline Water & q.b. 100 & q.b. 100 & q.b. 100 & q.b. 100 & q.b. 100 & q.b. 100 & q.b. 100 & q.b. 100 & q.b. 100 \\
\hline \multicolumn{10}{|l|}{ Phase C } \\
\hline Kathon CG & 0.05 & 0.05 & 0.05 & 0.05 & 0.05 & 0.05 & 0.05 & 0.05 & 0.05 \\
\hline Gram 1 & 0.35 & 0.35 & 0.35 & 0.35 & 0.35 & 0.35 & 0.35 & 0.35 & 0.35 \\
\hline \multicolumn{10}{|l|}{ Phase D } \\
\hline Parfum & 1.0 & 1.0 & 1.0 & 1.0 & 1.0 & 1.0 & 1.0 & 1.0 & 1.0 \\
\hline
\end{tabular}

\subsection{Sensory Evaluation}

Thirty female panelists (aged $28 \pm 6$ years), who had no training in sensory assessment techniques, participated in the study. Assessors were first introduced to the general concept of the study, following a detailed explanation of the test and used sensory descriptors. Namely, for each sensory attribute, the procedure, definition and descriptive terms were first demonstrated using standard materials that represent the extremes of sensory characteristics. To guarantee panel precision and reproducibility, the panelists were trained asking them to evaluate three commercial $\mathrm{O} / \mathrm{W}$ creams on the same attributes investigated for the present study. Assessors were explained how to pick up and apply the samples and 
how to evaluate each of the sensory characteristics. This assessment was carried out in triplicate, and subsequent two-way (repetition, assessors) analysis of variance was performed. The study was conducted in a laboratory with controlled temperature and relative humidity, and adequate light conditions. Panelists evaluated samples' characteristics during pick-up and rub-in phase, and after application. Assessors graded attributes using pre-defined descriptive terms, as reported in Table 2. Cream samples were presented in similar containers labeled with four-digit code numbers. The temperature of all samples distributed to the testers was the same (room temperature) and the samples were freshly prepared. The panelists received the cream samples and an analysis form, containing instructions to compare the formulations by indicating the descriptive term that better described the sensory attribute under evaluation. Each product (about $2 \mathrm{mg}$ ) was applied over the back of the left hand. The volunteers also reported which formulation they preferred.

Table 2. Description of attributes used for sensory evaluation.

\begin{tabular}{|c|c|c|}
\hline Phase & Sensory attribute & Description \\
\hline \multirow{3}{*}{ During pick-up } & Consistency & Liquid/semisolid \\
\hline & Adhesion & $\begin{array}{l}\text { Amount of sample that stays on forefinger after short contact }(2 \mathrm{~s}) \text { with sample in } \\
\text { container }\end{array}$ \\
\hline & Elasticity & $\begin{array}{l}\text { Degree to which product expands between thumb and forefinger-slightly } \\
\text { elastic/elastic/very elastic }\end{array}$ \\
\hline \multirow{4}{*}{ During rubbing } & Spreadability & $\begin{array}{l}\text { Impression of the area that the sample will cover while being rubbed } 8 \text { times in a } \\
\text { circular motion over the back of the hand }\end{array}$ \\
\hline & Stickiness & $\begin{array}{l}\text { Degree to which the sample feels sticky (force required to separate finger from } \\
\text { the skin)_not sticky/slightly sticky/sticky/very sticky }\end{array}$ \\
\hline & Oiliness & Degree to which the sample feels oily_not oily/slightly oily/oily/very oily \\
\hline & Absorbency & $\begin{array}{l}\text { Impression of the rate of absorption of the sample into the } \\
\text { skin-slow/moderate/fast }\end{array}$ \\
\hline \multirow{2}{*}{ After feel } & Sticky & $\begin{array}{l}\text { Degree to which the sample leaves the skin feeling sticky } 10 \text { min after } \\
\text { application-not sticky/slightly sticky/ sticky/very sticky }\end{array}$ \\
\hline & Oiliness & $\begin{array}{l}\text { Degree to which the sample leaves the skin feeling oily } 10 \mathrm{~min} \text { after } \\
\text { application-not oily/slightly oily/oily/ very oily }\end{array}$ \\
\hline
\end{tabular}

\subsection{Assessment of in Vivo Efficacy}

A panel of 20 healthy female volunteers (average age $25 \pm 4$ ), without dermatological diseases and with normal/moderate dry skin, participated in the study, after giving their informed consent. The local ethics committee declared that no approval was needed for this type of studies. Long-term (7 days) in vivo performance studies were carried out on emulsions A1 and A2. Measurements were taken under controlled temperature $\left(22 \pm 1{ }^{\circ} \mathrm{C}\right)$ and humidity $(35 \% \pm 5 \%)$ conditions, after 30 min of acclimatization period. The samples were applied on one side of the face and the other side was left as the non-treated control. A calibrated DermHair Analyzer Program (Vivipharma, San Marino) was used for the measurement of skin hydration and wrinkles. Volunteers were instructed to apply samples to the assigned sites 2 times a day (in the morning and in the evening). A group of 10 volunteers (casually chosen) applied emulsion A1 and the other group used emulsion A2. Measurements were taken at baseline prior to sample application and after 7 days. The volunteers were requested not to apply the 
emulsions the morning before the final measurement. The use of other cosmetic products was not allowed throughout the study, apart from for normal hygiene treatment. Statistical analysis of the results was performed using Students' t test $(p<0.05)$.

\section{Results and Discussion}

\subsection{Physicochemical Properties of Emulsions A-C}

All the emulsions were prepared using the same amount of oil phase $(12 \% w / w)$ and of emulsifier system $(5 \% \mathrm{w} / \mathrm{w})$. To assess the effect of oil phase composition on the emulsion physicochemical and sensory properties, the same amount $(2 \% w / w)$ of three different oils, commonly used in cosmetic products, were included in the formulation. These oils showed different lipophilicity as their $\log P$ values (calculated using Advanced Chemistry Development software Solaris V 4.67, Toronto, Canada) were: $\mathrm{DO}=12.94 ; \mathrm{MYR}=10.85 ; \mathrm{IPM}=7.43$. Similarly, emulsifier systems with different HLB values were tested (Tween 60/Span $60 \mathrm{HLB}=10.8$; Montanov $68 \mathrm{HLB}=10$; Brij 72/721 HLB =9).

As shown in Table 3, emulsions A-C showed similar $\mathrm{pH}$ values ranging from 6.5 to 6.9. All formulations showed pseudoplastic behavior, since viscosity decreased with increasing shear stress. This thixotropic behavior is considered desirable for topical preparations as it improves spreading of the product on the skin [23]. Comparison of the rheograms of $\mathrm{O} / \mathrm{W}$ emulsions containing different emulsifier systems and different oils but the same aqueous phase revealed that the shape of the obtained flow curves and hysteresis loops was similar (data not shown). Other authors [18] reported that emulsion flow behavior mostly depends on the rheological properties of continual phase rather than on the microstructure of the emulsion system (disperse phase). In our study, no relationship was observed between emulsion thixotropic behavior and emulsion composition. Viscosity values were influenced by both the emulsifier system and the oily phase composition but no clear relationship was observed between viscosity and emulsifier HLB or oil LogP.

Spreadability indicates the area on which a semi-solid topical formulation spreads on application to the skin. This parameter plays a key role in determining both the efficacy and the consumer acceptance of the product. A poor spreadability may result in an uneven distribution of the formulation on the skin, thus affecting the amount of the dose applied and the efficiency of active ingredient(s) skin permeation. On the other hand, consumers perceive a poor spreadability as a weakness of the product, which could lead to the choice of other products with a better performance, independently on their actual efficacy.

The emulsions investigated in this work showed spreadability $(\mathrm{S})$ values ranging from 4 to 7.5. While no significant difference of $\mathrm{S}$ was observed using different oils in emulsions containing Tween 60/Span 60, the addition of MYR or IPM had opposite effects compared to DO when Montanov 68 or Brij72/721 were used as emulsifiers (Table 3). These results pointed out that the different lipophilicity of oils and emulsifiers could not account for the obtained $\mathrm{S}$ values, suggesting that ingredients' interactions occurring in the emulsion structure could determine different textures, which affected formulation spreadability. Other authors reported a linear relationship between viscosity and spreadability for topical formulations [24,25] as the lower the viscosity of a cream, the lower the surface tension and the higher the spreadability on the skin. The lack of a relationship 
between emulsions' viscosity and in vitro spreadability observed in our study could be due to the method we chose to perform in vitro spreadability measurements. This method is regarded as easy to perform and suitable for routine evaluations [25] but it does not involve any shear stress of the sample, in contrast with other commonly used techniques. Therefore, features such as the rigidity and yield stress of the product in its semi-solid condition, prior to the determination of spreadability values with such method, could affect the results, leading to a lack of relationship between viscosity and spreadability. Hence, our results evidence that the method used to determine the spreadability of topical products should be carefully chosen to obtain a linear relationship with viscosity values.

As reported in the literature, the occlusive effect of the formulation can influence SC hydration, particularly in long-term applications, and may enhance drug skin permeation [26].

The occlusive properties of $\mathrm{O} / \mathrm{W}$ emulsions may depend on the type and amount of oils used [27] and on the volume of the oily phase [28]. To evaluate the effect of oil lipophilicity on emulsion properties, in this work the amount of oils and the volume of oily phase were maintained constant in the different formulations tested.

Comparing $F$ values obtained for emulsions A-C, we observed that the type of oils and of emulsifier system affected the occlusive properties of the formulations under investigation. Using MYR, emulsions significantly less occlusive than those containing the same emulsifiers but the other two oils were obtained. This effect was less evident for formulations prepared using the most lipophilic emulsifier system (Brij 72/721), suggesting that emulsion occlusive properties could be modulated by selecting proper combinations of oil phase and emulsifiers.

All emulsions proved stable during one year of storage at room temperature as no significant change of aspect, odor, and physicochemical parameters was observed (data not shown).

Table 3. Physicochemical properties, $\mathrm{pH}$, viscosity, spreadability $(S)$, occlusion factor $(F)$, of emulsions A-C.

\begin{tabular}{ccccc}
\hline Sample & $\mathbf{p H}$ & Viscosity $(\mathbf{c P s})$ & $\boldsymbol{S} \pm \mathbf{S D}(\mathbf{c m})$ & $\boldsymbol{F} \pm \mathbf{S D}$ \\
\hline $\mathrm{A}$ & 6.56 & 18,500 & $4.85 \pm 0.15$ & $45.4 \pm 1.8$ \\
$\mathrm{~A} 1$ & 6.50 & 16,100 & $7.25 \pm 0.25$ & $24.6 \pm 3.0$ \\
$\mathrm{~A} 2$ & 6.89 & 14,300 & $7.50 \pm 0.10$ & $45.6 \pm 2.8$ \\
$\mathrm{~B}$ & 6.66 & 19,300 & $4.38 \pm 0.37$ & $28.2 \pm 6.6$ \\
$\mathrm{~B} 1$ & 6.59 & 19,200 & $4.63 \pm 0.13$ & $3.0 \pm 1.8$ \\
$\mathrm{~B} 2$ & 6.58 & 24,100 & $4.18 \pm 0.33$ & $32.8 \pm 2.8$ \\
$\mathrm{C}$ & 6.92 & 10,700 & $6.38 \pm 0.12$ & $25.2 \pm 4.8$ \\
$\mathrm{C} 1$ & 6.52 & 14,400 & $4.05 \pm 0.20$ & $7.2 \pm 0.4$ \\
$\mathrm{C} 2$ & 6.92 & 16,000 & $4.13 \pm 0.13$ & $60.2 \pm 2.6$ \\
\hline
\end{tabular}

\subsection{Sensory Evaluation}

In the training phase of the panelists, ANOVA (Analysis of variance) showed that between-repetition and between-assessor variations were not significant $(p>0.05)$. To evaluate the sensory properties of emulsions A-C, assessors were request to express their opinion in three different phases of the topical application procedure: (a) removal of the sample from the container; (b) sensations during the spreading on the skin; (c) final impression due to the residue remaining on the skin. During the pick-up 
phase, the majority of the panelists $(60 \%)$ indicated that all the emulsions tested had a good adhesion, without pointing out a significant difference among the different products. The consistence of emulsion A1, A2, B1, and B2 was defined as "good" by at least $60 \%$ of the assessors while at the remaining formulations a good consistence was attributed by a minority of the panelists $(30 \%-40 \%)$. These evaluations did not seem to correlate well with the viscosity of the formulations under investigation as the viscosity of emulsion B was similar to that of emulsion B1 and the viscosity of emulsions A1 and A2 was lower than that of emulsions A and B. About 50\% of the assessors defined all the emulsions as elastic while the other $50 \%$ attributed to the same emulsions a low elasticity. Therefore, this parameter did not provide any useful information about the effect of incorporating different ingredients on the sensory properties of these formulations.

As regards the evaluations during the spreading of the product on the skin, at least $50 \%$ of the panelist attributed the term "oily" to all emulsions, apart from A, A1, A2, thus suggesting that the type of emulsifiers system may significantly affect the sensation of oiliness during the application of the product. As shown in Figure 1, different trends were obtained from the sensory evaluation of emulsions A-C but no clear relationship was observed between the type of oil used in the oily phase or the different emulsifiers and the other parameters evaluated by the panelists. The perceived spreadability during application of the product did not reflect the spreadability values determined using an in vitro technique, likely because (a) other concomitant factors, such as oiliness or absorbency, affected the opinion of the panelists; (b) our in vitro method was not adequate to predict the sensorial evaluation.

Other authors reported close relationships between instrumental data and sensory evaluations of cosmetic products. Lukic et al. [29] modified the oil phase composition of W/O emulsions in one component to evaluate the effect of this alteration on emulsion rheological and textural properties. This study evidenced that sensory attributes used for the description of the product in pick-up and rub-out phase, could be predicted by instrumental (rheological and textural) measurements. Gilbert et al. [30], studying the texture of nine $\mathrm{O} / \mathrm{W}$ cosmetic emulsions, only varying by their polymeric constituent, reported that rheology and texture analysis could be used to predict sensory texture attributes of cosmetic emulsions. However, a study performed to assess the effect of thickeners on the rheological and sensory characteristics of $\mathrm{O} / \mathrm{W}$ cosmetic lotions evidenced a linear relationship only between two sensory attributes and three parameters derived from rheological measurements [31]. In our study, we modified simultaneously two components of our $\mathrm{O} / \mathrm{W}$ emulsions, i.e., the emulsifier system and one constituent of the oil phase. These changes led to products whose perceived oiliness outweighed the other sensory attributes, thus masking the effects of emulsifiers and oils modification on the sensory attributes of these emulsions and making difficult to correlate instrumental and sensory data. Similarly, Gonçalves et al. [32] reported that the sensations of oiliness and stickiness promoted by the formulations were determinants in the answers given by the panelists. As some sensory attributes, such as oiliness, have a strong influence on hedonic response, this hedonic aspect may lead to a nonlinear relationship between a sensory attribute and other measurable parameters [33].

In the third phase (final impression due to the residue remaining on the skin), a trend similar to that of the first phase was observed as emulsions A, A1 and A2 were considered less oily than the other formulations and no significant different in the stickiness was noted. 
When the panelists were requested to express their preference, $50 \%$ of them indicated emulsion A1 as the best product while the other 50\% regarded emulsion A2 the optimal formulation. Therefore, these two emulsions were investigated in vivo to assess their efficacy after a long-term application.

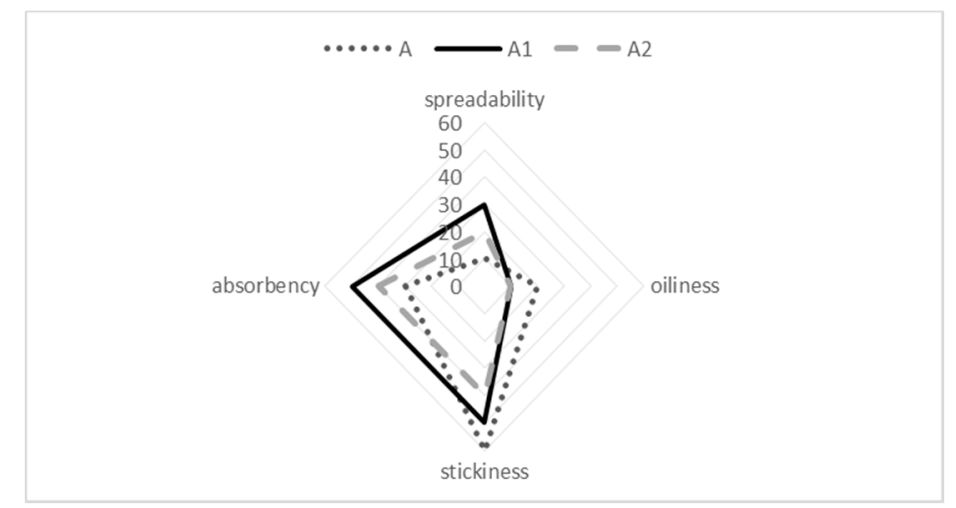

(a)

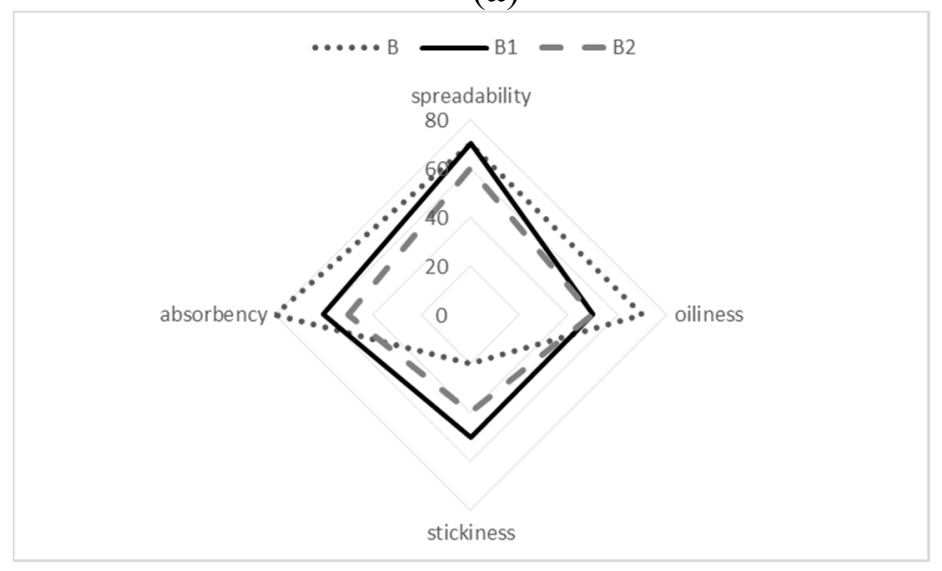

(b)

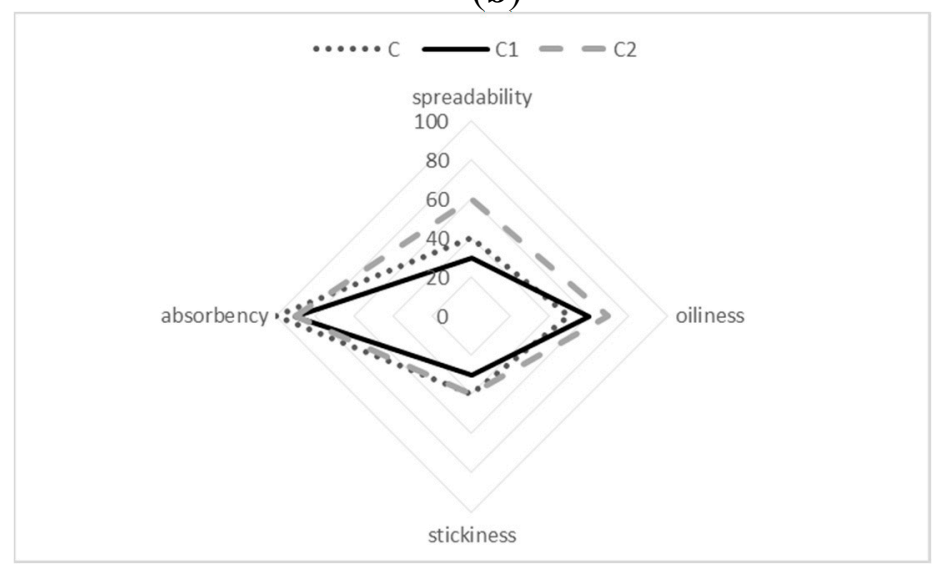

(c)

Figure 1. Sensory evaluation of emulsions A-C during the application on the skin. (a) emulsions A, A1 and A2; (b) emulsions B, B1 and B2; (c) emulsions C, C1, C2.

\subsection{Assessment of in Vivo Efficacy}

After applying emulsion A1 or A2 for 7 days, a significant increase of skin hydration was observed compared to the control (Table 4). As emulsion A2 contained IPM, a well-known skin permeation enhancer [34], and showed higher occlusive properties, it was expected to be more effective than 
emulsion A1. On the contrary, both emulsions provided similar percentages of hydration improvement, pointing out that these formulations had the same efficacy in vivo despite their different composition and physicochemical properties. These results suggest that other factors such active ingredient release from the vehicle and partitioning into the skin, may be involved in determining the effectiveness of a topical formulation. In addition, as Cartigliani et al. [35] reported that the improvement of skin hydration after cosmetic treatments was age-related, the lack of any difference between emulsion A1 and A2 could be attributed to the enrollment for our study of young women who did not show evident signs of skin ageing.

In Figure 2, diagrams representing wrinkle distribution in two subjects before and after treatment with emulsion A1 and A2 are reported. A slight improvement of facial wrinkles was observed after a 7 days treatment in four subjects who applied emulsion A1 and in five subjects who applied emulsion A2. However, this improvement could not be regarded statistically significant, as the instrument did not allow a rigorous quantification of wrinkle depth and extension before and after treatment.

Table 4. Skin hydration before treatment (Day 0) and after 7 days treatment (Day 7) with emulsion A1 or A2.

\begin{tabular}{cccc}
\hline Sample & Day 0 & Day 7 & \% increase \\
\hline Control $^{\text {a }}$ & $37.4 \pm 10.2$ & $38.9 \pm 11.3$ & - \\
A1 & $38.6 \pm 11.0$ & $66.3 \pm 12.3^{\mathrm{b}}$ & 47.6 \\
A2 & $36.6 \pm 12.7$ & $62.0 \pm 10.2^{\mathrm{b}}$ & 43.0 \\
\hline${ }^{\mathrm{a}}$ No treatment; ${ }^{\mathrm{b}}$ Difference statistically significant $(p<0.05)$.
\end{tabular}

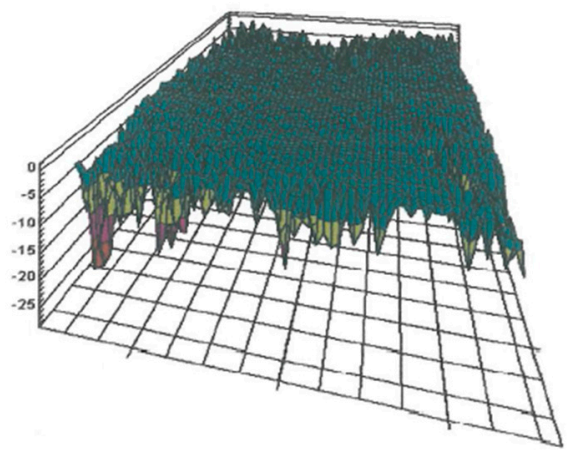

(a)

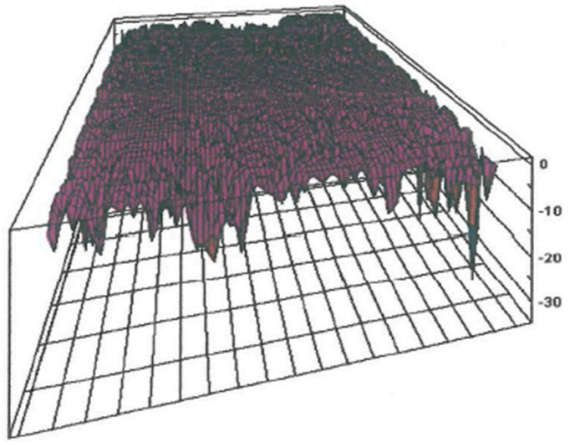

(c)

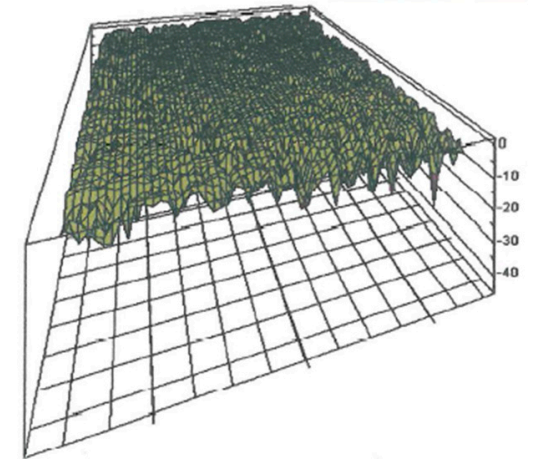

(b)

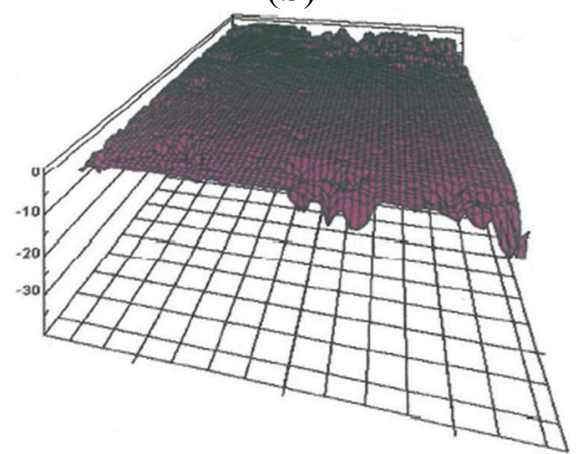

(d)

Figure 2. Diagrams of facial wrinkles before (a) and after (b) treatment with emulsion A1 and before (c) and after (d) treatment with emulsion A2. 


\section{Conclusions}

The results of this study evidenced that both the oily phase composition and the type of emulsifier systems affected the physicochemical and the sensory properties of cosmetic $\mathrm{O} / \mathrm{W}$ emulsions containing vitamin E acetate. Emulsion spreadability and occlusive properties could be modulated by selecting different combinations of oily phase and emulsifiers. However, no clear relationship was observed between emulsion physicochemical properties and sensory properties. In this work, the oiliness of the formulation seemed to be a predominant factor, along with absorbency, in determining the favor of the volunteers involved in the study.

A better understanding of the relationship between emulsion physicochemical properties and sensory characteristics could be helpful to predict the performance of a cosmetic product and to choose the most suitable ingredients to design a successful formulation.

\section{Author Contributions}

Author L.M. designed the experimental protocol, wrote the manuscript and supervised the entire work. Author L.R. and C.M. performed all the measurements and analyzed the results. Author G.P. supervised in vivo studies.

\section{Conflicts of Interest}

The authors declare no conflict of interest.

\section{References}

1. Traber, M.G.; Sies, H. Vitamin E in humans: Demand and delivery. Annu. Rev. Nutr. 1996, 16, 321-347.

2. Thiele, J.J.; Schroeter, C.; Hsieh, S.N.; Podda, M.; Packer, L. The antioxidant network of the stratum corneum. Curr. Probl. Dermatol. 2001, 29, 26-42.

3. Rangarajan, M.; Zatz, J.L. Skin delivery of vitamin E. J. Cosmet. Sci. 1999, 50, 249-279.

4. Pinnell, S.R. Cutaneous photodamage, oxidative stress and topical antioxidant protection. J. Am. Acad. Dermatol. 2003, 48, 1-22.

5. Krol, E.S.; Kramer-Stickland, K.A.; Liebier, D.C. Photoprotective actions of topically applied vitamin E. Drug Metab. Rev. 2000, 32, 413-420.

6. Ritter, E.F.; Axelrod, M.; Minn, K.W.; Eades, E.; Rudner, A.M.; Serafin, D.; Klitzman, B. Modulation of ultraviolet light-induced epidermal damage: beneficial effects of tocopherol. Plast. Reconstr. Surg. 1997, 100, 973-980.

7. Tavakkol, A.; Nabi, Z.; Soliman, N.; Polefka, T.G. Delivery of vitamin E to the skin by a novel liquid skin cleanser: Comparison of topical versus oral supplementation. J. Cosmet. Sci. 2004, 55, 177-187.

8. Bissett, D.L.; Hillerbrand, G.G.; Hannon, D.P. The hairless mouse as a model of skin photoaging: Its use to evaluate photoprotective materials. Photodermatology 1989, 6, 228-233.

9. Mayer, P. The effects of vitamin E on the skin. Cosmet. Toilet. 1993, 108, 99-109. 
10. Rona, C.; Vailati, F.; Berardesca, E. The cosmetic treatment of wrinkles. J. Cosmet. Dermatol. 2004, 3, 26-34.

11. Norkus, E.P.; Bryce, G.F.; Bhagavan, H.N. Uptake and bioconversion of $\alpha$-tocopheryl acetate to $\alpha$-tocopherol in skin of hairless mice. Photochem. Photobiol. 2008, 57, 613-615.

12. Baschong, W.; Artmann, C.; Hueglin, D.; Roecling, J. Direct evidence of bioconversion of vitamin E acetate in to vitamin E: An ex vivo study in viable human skin. J. Cosmet. Sci. 2001, 52, $155-161$.

13. Chiu, A.; Kimball, A.B. Topical vitamins, minerals and botanical ingredients as modulators of environmental and chronological skin damage. Br. J. Dermatol. 2003, 149, 681-691.

14. Gaspar, L.R.; Campos, P.M. Photostability and efficacy studies of topical formulations containing UV filters combination and vitamins A, C and E. Int. J. Pharm. 2007, 343, 181-189.

15. Almeida, I.F.; Gaio, A.R.; Bahia, M.F. Hedonic and descriptive skin feel analysis of two oleogels: Comparison with other topical formulations. J. Sens. Stud. 2008, 23, 92-113.

16. Husson, F.; Le, S.; Pages, J.F. Variability of the representation of the variables resulting from PCA in the case of a conventional sensory profile. Food Qual. Prefer. 2007, 18, 933-937.

17. Parente, M.E.; Ares, G.; Manzoni, A.V. Application of two consumer profiling techniques to cosmetic emulsions. J. Sens. Stud. 2010, 25, 685-705.

18. Lukic, M.; Jaksic, I.; Krstonosic, V.; Cekic, N.; Savic, S. A combined approach in characterization of an effective W/O hand cream: the influence of emollient on textural, sensorial and in vivo skin performance. Int. J. Cosmet. Sci. 2012, 34, 140-149.

19. Montenegro, L.; Carbone, C.; Paolino, D.; Drago, R.; Stancampiano, A.H.; Puglisi, G. In vitro skin permeation of sunscreen agents from O/W emulsions. Int. J. Cosmet. Sci. 2008, 30, 57-65.

20. Purushothamrao, K.; Khaliq, K.; Sagare, P.; Patil, S.; Kharat, S. Formulation and evaluation of vanishing cream for scalp psoriasis. Int. J. Pharm. Sci. Tech. 2010, 4, 32-31.

21. Chaudhary, B.; Verma, S. Preparation and evaluation of novel in situ gels containing acyclovir for the treatment of oral herpes simplex virus infections. Sci. World J. 2014, 2014, 1-7.

22. Wissing, S.A.; Lippacher, A.; Muller, R.H. Investigations on the occlusive properties of solid lipid nanoparticles (SLN). J. Cosmet. Sci. 2001, 52, 313-324.

23. Gaspar, L.R.; Campos, P.M. Rheological behavior and the SPF of sunscreens. Int. J. Pharm. 2003, 250, 35-44.

24. Lardy, F.; Vennat, B.; Pouget, M.P.; Pourrat, A. Functionalization of hydrocolloids: Principal component analysis applied to the study of correlations between parameters describing the consistency of hydrogels. Drug Dev. Ind. Pharm. 2000, 26, 715-721.

25. Garg, A.; Aggarwal, D.; Garg, S.; Singla, A.K. Spreading of semisolid formulations: An update. Pharm. Technol. 2002, 26, 84-105.

26. Fluhr, J.; Holleran, W.M.; Berardesca, E. Clinical effects of emollients on skin. In Cosmetic Science and Technology Series: Skin Moisturization; Leyden, J.J., Rawlings, A.V., Eds.; Marcel Dekker Inc.: New York, NY, USA, 2002; pp. 220-242.

27. Black, D.; Diridollou, S.; Lagarde, J.M.; Gall, Y. Skin care products for normal, dry and greasy skin. In Textbook of Cosmetic Dermatology; Baran, R., Maibach, H.I., Eds.; CRC Press: London, UK, 1998; pp. 125-150. 
28. Wissing, S.A.; Müller, R.H. The influence of the crystallinity of lipid nanoparticles on their occlusive properties. Int. J. Pharm. 2002, 242, 377-379.

29. Lukic, M.; Jaksic, I.; Krstonosic, V.; Dokic, L.; Savic, S. Effect of small change in oil phase composition on rheological and textural properties of W/O emulsion. J. Texture Stud. 2013, 44, $34-44$.

30. Gilbert, L.; Savary, G.; Grisel, M.; Picard, C. Predicting sensory texture properties of cosmetic emulsions by physical measurements. Chemometr. Intell. Lab. 2013, 124, 21-31.

31. Moravkova, T.; Filip, P. The influence of thickeners on the rheological and sensory properties of cosmetic lotions. Acta Polytech. Hung. 2014, 11, 173-186.

32. Gonçalves, G.M.S.; Srebernich, S.M.; Alves de Macedo Souza, J. Stability and sensory assessment of emulsions containing propolis extract and/or tocopheryl acetate. Braz. J. Pharm. Sci. 2011, 47, 585-592.

33. Klicast, D.; Clegg, S. Sensory perception of creaminess and its relationship with food structure. Food Qual. Prefer. 2002, 13, 609-623.

34. Engelbrecht, T.N.; Demé, B.; Dobner, B.; Neubert, R.H.H. Study of the influence of the penetration enhancer isopropyl myristate on the nanostructure of stratum corneum lipid model membranes using neutron diffraction and deuterium labelling. Skin Pharmacol. Physiol. 2012, 25, 200-207.

35. Cartigliani, C.; Bonfigli, A.; Brancato, S.; Rigano, L. The age factor in the cosmetic management of biophysical skin parameters. Cosmetics 2014, 1, 117-127.

(C) 2015 by the authors; licensee MDPI, Basel, Switzerland. This article is an open access article distributed under the terms and conditions of the Creative Commons Attribution license (http://creativecommons.org/licenses/by/4.0/). 